DOI: 10.17234/SRAZ.65.30

UDK: 821.134.3(81)-9.09

Original scientific paper

Recebido a 3 de maio de 2020

Aceite para a publicação a 25 de novembro de 2020

\title{
A crônica brasileira urbana: um subgênero em transição
}

\author{
Dário Borim Jr. \\ Universidade de Massachusetts Dartmouth \\ dborim@umassd.edu
}

Com ênfase sobre panoramas da vida urbana, o objetivo deste ensaio é descobrir, desvelar e definir a natureza e o entroncamento das principais linhas evolutivas de um subgênero da crônica brasileira, das quais resultaram o que hoje vislumbramos como crônica contemporânea - aquela que gradualmente se configurou após a chegada da internet e a consolidação da mídia eletrônica, seja esta de convívio social, entretenimento, informação ou notícias.

Palavras-chaves: cidade, crônica, gênero, jornalismo, literatura

\section{Formações híbridas}

A crônica raramente tem a sua origem questionada: trata-se do feuilleton, ou folhetim, como passou a ser chamada em português, aquela seção criada na parte inferior da primeira página dos jornais franceses a partir de 28 de janeiro de 1800, quando o periódico parisiense Journal des Débats estabeleceu a sua pioneira abertura para um novo tipo de redação jornalística. O novo espaço publicava anúncios pagos de variada natureza, mas, principalmente, logo permitiria a edição de pequenas matérias sobre teatro e outros eventos culturais, agora redigidas com uma pequena dose de subjetividade. Haveria liberdade, também naquele espaço, para a enunciação de notícias com uma pitada de variação no seu tom, um tom que, lenta e gradualmente, foi abrindo brechas para o humor e a ironia.

No Brasil do início do século XIX, alguns dos jornais da capital eram redigidos parcial ou totalmente em francês, como L'independent, de 1827, ou eram bilíngues, como O Moderador, de 1831, informa-nos Marcos Vinícius Nogueira Soares (2014: 12-13). A onda do folhetim vai mesmo se afirmar e se estabelecer além daquela posição de roda-pé na primeira página. Estava modelada, assim, a janela para os romances em série. Adquirindo feitios próprios e ao mesmo tempo influenciando outras formas de textos publicados em jornais, até mesmo a redação de notícias, às mãos de um João do Rio ou de um Paulo Barreto, por exemplo, solidificava-se rapidamente o caráter nacional de um gênero. 
Mas que gênero? Humberto Werneck ecoa o que dizia o poeta Mário de Andrade a respeito do conto: crônica "é tudo aquilo que chamamos de crônica" (Werneck 2005: 7). Quase tudo, continua Werneck, "cabe nesse rótulo ecumênico, da pequena peça de ficção ao poema em prosa, passando pela reflexão acerca de miudezas do cotidiano" (7). Nos extremos dessas formações híbridas, pondera: "A própria falta de assunto, volta e meia, vira assunto" (7). "Eternamente deleitável ou imediatamente deletável", arremata Werneck (7), a crônica "depende menos do tema do que das artes do autor".

\section{Estigmas e superações}

Em 1961, Paulo Rónai foi capaz de capturar algumas das razões pelas quais críticos de valor negavam à crônica a condição de gênero literário. Natural de Budapeste, mas brasileiro de coração, Rónai destaca a ambiguidade do texto curto que seduziu o Brasil e argumenta que esse tipo de composição parte do "pendor natural de quem o maneja" (Rónai 2014: 221). O cronista, continua Rónai, "tende ora para o poema em prosa, ora para o conto, ora para o ensaio, ora para o comentário" (221). O que assim se escreve, conclui, "parece irremediavelmente condenado à transitoriedade" por causa do "caráter passageiro dos próprios periódicos que o abrigam" (221).

Engano é pensar que tal veredito preconizado por Rónai se aplica a todos os espécimes do gênero. Seja do ponto de vista artístico, seja do ponto de vista sócio-histórico, a crônica não deveria ser considerada uma escrita simplesmente efêmera. Examinando a produção de crônicas em vários países da América Latina, e a obra de alguns modernistas de grande destaque, como Mário de Andrade, em particular, Viviane Mahieux argumenta que a crônica de fato contribuiu para a modernidade literária de dois modos. Por um lado, a crônica propôs uma ideia de literatura que não é exclusivamente focada no valor que um texto específico terá ao longo do tempo. A literatura passou a ser considerada dentro de um âmbito cultural onde predomina uma experiência estética muito mais diversa do que àquelas anteriores ao Modernismo (Mahieux 2011: 30).

Desse modo, a literatura pode ser continuamente recriada e renovada, num contexto de evolução cultural, pela intensa publicação e circulação de textos que, em muitos casos, poderão ser de vida bastante curta (Mahieux 2011: 30). Por outro lado, defende Mahieux (30), ao pensarmos no que é literário como algo além do literário apenas enquanto arte, observamos que "a crônica alarga as dimensões da cidade letrada no sentido de encorporar em si mesma tanto a cultura literária quanto a cultura popular". A crônica, por esse viés, pôde "desempenhar um papel instrumental na expansão - e, até certo ponto, na democratização - da cidade das letras no início do século XX" (Mahieux 2011: 30). Mahieux destaca o fato de que ao refletir sobre a sua própria trajetória intelectual, Andrade se autodefiniu como um "agente de mudanças" que se fez "muito mais humano", talvez com um destino menos divino do que o de criar a tranquilidade, o prazer, ou "a evasão desse mundo que a Beleza nos proporciona" (Mahieux 2011: 68). 
Subjetivamente de maior ou menor "beleza", o escritor Moacir Amâncio, defende a noção de que enquadrar a crônica como gênero menor "esbarra na evidência de que não existem gêneros menores" (Amâncio 2014: 226). Há, sim, diz ele, "grandes e pequenos romancistas, grandes e pequenos poetas, grandes e pequenos contistas" (Amâncio 2014: 226). Quando comparadas ao conto, por exemplo, é um equívoco imaginar que as crônicas "seriam apenas histórias breves, inferiores ao conto em qualidade, densidade, ou qualquer outro substantivo invocado" (Amâncio 2014: 226). A crônica, então, não seria mais que um "conto leve e leviano". Mas como aplicar tal definição, arremata Amâncio (216), "às obras-primas de um Rubem Braga ou de um Fernando Sabino?".

\section{Época de ouro}

Contribuindo significativamente não apenas para a permanência mas também para a consagração estética do gênero dito "menor" ou "efêmero", as crônicas nos meados do século XX começaram aparecer abundantemente em formato de livro. Mesmo assim, alguns críticos não se impressionaram. Talvez nostálgico sobre algo em permanente transformação e purista diante daquilo que não tem fórmula fixa, Alceu Amoroso Lima, por exemplo, escreveu que "uma crônica, num livro, é como um passarinho afogado" (Lima apud Werneck 2005: 11).

Apesar do que ainda restava de visões reducionistas, muitos críticos literários finalmente passaram a questionar aqueles estigmas. Poucas décadas depois, muitos pensadores, como Antonio Candido, passaram a celebrar traços típicos da crônica e suas contribuições para a literatura e para a cultura como um todo. Para Candido (1992: 22), a crônica brasileira "bem realizada participa de uma língua geral lírica, irônica, casual, ora precisa e ora vaga, amparada por um diálogo rápido e certeiro, ou por uma espécie de monólogo comunicativo". Candido destaca as decrescentes intenções da crônica de informar e comentar, típicas do jornalismo, para ficar com o intento de, sobretudo, divertir. Ele nota como "a linguagem se tornou mais leve, mais descompromissada e (fato decisivo) se afastou da lógica argumentativa ou da crítica política, para penetrar poesia adentro" (Candido 1992: 15). Com o seu poder de síntese, o professor definiu seu entendimento da "fórmula moderna" da crônica. Ali entra "um fato miúdo e um toque humorístico, com o seu quantum satis de poesia" (15). Representa, assim, "o amadurecimento e o encontro mais puro da crônica consigo mesma" (15).

Esse momento de grandes transformações é marcado também pela participação das mulheres na produção da crônica brasileira, entre elas se destacando, por exemplo, nas décadas de 1950 a 1970, as obras de Clarice Lispector, Rachel de Queiroz e Dinah Silveira de Queiroz. Isso transcorre em meio a uma fase ao mesmo tempo, clássica (porque modelar e poética), moderna (porque revolucionária e sucinta), ou, mesmo, gloriosa (porque estelar e popular), da crônica brasileira. Era a era dos primeiros escritores a desenrolar suas carreiras quase que exclusivamente dedicadas à crônica. Transcorria, então, a fase de ouro do gênero, marcada pela excelência estética dos textos das escritoras acima e pelas 
pérolas de outros imortais da crônica, textos onde se encontram o refinamento da linguagem astuta e lapidada, o prazer pessoal e o aprendizado intelectual através da leitura.

\section{Tempos do sem-fio}

Ainda por aqueles áureos tempos da crônica do século XX, havia um fator de apoio a autores. Era a acentuada presença de editoras de livros, revistas e jornais de maior prestígio e o poder financeiro para remunerar os autores pela escrita das crônicas nas capitais estaduais e, em particular, no eixo Rio de Janeiro-São Paulo. Os ventos, porém, mudariam de direção. Das forças centrípetas os ventos passaram a fluir com as novas forças centrífugas soprando sobre o território nacional na última década do século XX. Era a descentralização dos órgãos de imprensa e editoração, fenômeno crescente até o momento em que centenas de jornais e revistas começaram a fechar as portas. A concorrência com as publicações online de fato condenou boa parte da imprensa tradicional à falência.

Por outro lado, surgiram inúmeras oportunidades para se escrever, publicar e interagir com leitores em processo tão rápido e tão abrangente que nunca se pôde imaginar. Através de blogs, podcasts, lives e outras disseminações eletrônicas, as crônicas de prolíficos autores contemporâneos hoje são best-sellers. Entre eles, dois gaúchos se destacam: Martha Medeiros, vencedora do Prêmio Jabuti para coletâneas de crônicas, e Fabrício Carpinejar, autor de trinta e quatro livros. Medeiros e Carpinejar hoje atingem a centenas de milhares de leitores em poucas semanas após o lançamento de cada texto em seus portais oficiais e em dezenas de outros websites. Em ambos os casos, vigora a preocupação com o retratamento analítico, humorístico e poético de uma pletora de temas, praticamente um subgênero da crônica voltado para os conflitos da vida atual, da cultura de massas e do cotidiano urbano. Ambos os cronistas assim remexem e instigam os leitores por dentro ou por fora, tanto nas esferas domésticas e pessoais quanto no âmbito social e político.

No contraponto dos conflitos vários de nossa era, outros autores acentuam duas das mais assíduas características tradicionais da crônica brasileira: o tom humorístico e a preocupação com questões linguísticas. Walter Navarro, por um lado, é exímio nos jogos de palavras, muitos dos quais em ataque aberto sobre políticos corruptos. Maria Esther Maciel, por seu turno, investiga as competências linguísticas de diversos pássaros. Talvez ainda mais atraído por sarcasmo e ironia, Mentor Muniz Neto faz pilhéria não apenas do seu próprio nome, como também de maus hábitos da fala e aberrações das comunicações nos nossos tempos. Ele compõe seu segundo livro de crônicas como se faz uma colcha de retalhos que não mostra nada senão muitas de suas postagens no Facebook, textos curtos que ele endereçara aos seus mais de 120 mil seguidores.

Apresentados em ordem cronológica, a maioria dos textos de Muniz Neto parece resultar de pequenas (mas hilárias) ações do cotidiano e outras observações do dia a dia numa cidade grande. Muniz Neto nota e faz chacota, por exemplo, das idiossincrasias no comportamento das pessoas que aguardam na fila para 
retirar dinheiro de caixas automáticos. Ele simplesmente adora ouvir conversa alheia e recontar histórias de pessoas desconhecidas captadas anonimamente em shopping centers, farmácias, restaurantes e elevadores.

A vida urbana, questão central nas pioneiras crônicas, continua mesmo mais forte do que nunca. Sob os olhares de Vanessa Barbosa e Mariana Ianelli, por exemplo, coloridos, dinâmicos e poéticos murais daquelas cidades e sua gente retratam os modos peculiares de vida no centro e nas periferias de São Paulo. Residindo no Brasil por alguns anos, a jornalista portuguesa Alexandra Lucas Coelho, por seu turno, transporta os leitores aos distritos boêmios e lendários, além das favelas transformadas pelo turismo internacional no Rio de Janeiro. Os distritos do sexo e os bastidores das igrejas católicas e judaicas de Araxá, Rio de Janeiro e Recife se clareiam nas letras de Fernando Barreto, Urariano Mota e Marcelo Moutinho. São ali inúmeras as narrativas de humor e de tom agridoce sobre estranhos comportamentos em público de indivíduos anônimos e desconhecidos, como os de moradores de rua, prostitutas, sujeitos visivelmente solitários e doentes mentais. Por outro lado, cores e sons das vilas e vilarejos da Região Amazônica em Coelho constituem-se contrapontos às vozes de vendedores de frutas pelas ruas de cidades pequenas, como Cataguases, na obra de Luiz Ruffato, ou mesmo aos grunhidos de gatos peregrinos e pássaros cantantes na capital do Paraná, nas crônicas de Luís Henrique Pellanda.

\section{Conclusão}

Após as três primeiras fases da crônica (antiga, modernista e estelar), ${ }^{1}$ vivemos agora a era pós-moderna, de textos mediados pelo imediatismo e facilidade das comunicações interpessoais das mídias sociais eletrônicas, dos milhares de websites, e dos bilhões de contas e canais no WhatsApp, Facebook, Instagram, e YouTube. Parece-nos correto então traçar uma analogia: assim como a crônica modernista democratizou a literatura como um todo através periódicos dos anos de 1930, a internet agora democratiza crônica em si mesma, ao tornar sua produção e recepção uma realidade ultra-ligeira e acessível a todos. ${ }^{2}$

Apesar de estarem em gradativa extinção, os volumes impressos ainda se mantêm presentes, é claro. Entre os 35 livros de crônicas e sobre crônicas por nós examinados nos últimos três anos para um periódico da Biblioteca do Congresso dos Estados, ${ }^{3}$ um dos eixos temáticos mais explorados engloba os estilos de vida e ambientes do cotidiano em diferentes cidades, grandes ou pequenas, do Brasil e mundo afora. No substrato de acontecimentos históricos, de âmbito local, regional ou nacional, ou nas malhas do cotidiano, de vendedores ambulantes, de crianças brincando nos parques, ou de cães e gatos sem dono e sem rumo,

1 Para uma excelente seleção de crônicas divididas por fases cronológicas mais específicas, ver Santos.

2 Para uma discussão mais detalhada dessa realidade, ver Borim.

3 Por mais de dez anos (2009 e 2019) redigimos a seção "Brazilian Crônicas" do Handbook of Latin American Studies. 
as crônicas brasileiras contemporâneas perfilam, sob a poderosa influência da internet e do imediatismo das comunicações eletrônicas, um Brasil de dinâmicas e temáticas urbanas muito além das que nos mostravam Machado de Assis, José de Alencar, Lima Barreto ou João do Rio. Evoluindo estrutural e esteticamente ao longo de quase dois séculos, as crônicas de hoje se voltam para cidades que adquirem uma representação emocional e tridimensional nas mãos e mentes de grandes e audaciosos cronistas. Renovando o subgênero urbano em constante transição, poetas em prosa e contadores de casos fazem-se porta-vozes dos dramas e deleites de nossa era.

\section{Obras citadas}

Amâncio, Moacir (2014). A crônica, in: Crônicas Brasileiras: A Reader [eds. Charles A. Perrone, Dário Borim Jr. e Celia Bianconi], Gainsville, EUA: UP of Florida, pp. 226-227.

Barbosa, Vanessa (2014). O louco de palestra: e outras crônicas urbanas. São Paulo: Companhia das Letras.

Barreto, Fernando (2011). Sob o céu de Araxá: Crônicas. Montevidéu: aBrace.

Borim Jr, Dário (2014). Plugada no dia-a-dia: A crônica no século XXI, in: Crônicas Brasileiras: A Reader [eds. Charles A. Perrone, Dário Borim Jr. e Celia Bianconi], Gainsville, EUA: UP of Florida, pp. 234-239.

Candido, Antonio (1992). A vida ao-rés do chão, in: A crônica. O gênero, sua fixação e suas transformações no Brasil [ed. Antonio Candido], Rio de Janeiro/Campinas: UNICAMP/Rui Barbosa, pp. 13-22.

Carpinejar, Fabrício (2010). Mulher perdigueira. Rio de Janeiro: Bertrand.

Coelho, Alexandra Lucas (2013). Vai, Brasil. Lisboa: Tinta da China.

Ianelli, Mariana (2013). Breves anotações sobre um tigre: crônicas. Porto Alegre: Ardotempo.

Maciel, Maria Esther (2014). A vida ao redor: crônicas. Belo Horizonte, Brasil: Scriptum.

Mahieux, Viviane (2011). Urban Chroniclers in Modern Latin America: The Shared Intimacy of Everyday Life. Austin, EUA: U. of Texas P.

Medeiros, Martha (2013). A graça da coisa. Porto Alegre, Brasil: L\&PM.

Mota, Urariano (2014). Dicionário amoroso do Recife. Anagé, Brasil: Casarão do Verbo.

Moutinho, Marcelo (2015). Na dobra do dia: crônicas. Rio de Janeiro: Rocco.

Navarro, Walter (2011). Creme e castigo: 100 crônicas escolhidas e ilustradas, 19962011. Belo Horizonte, Brasil: Editora C/Arte.

Pellanda, Luís Henrique (2016). Detetive à deriva. Porto Alegre, Brasil: Arquipélago.

Perrone, Charles A., Dário Borim Jr. e Celia Bianconi, eds. (2014). Crônicas Brasileiras: A Reader. Gainsville, EUA: UP of Florida.

Rónai, Paulo (2014). Um gênero brasileiro: A crônica, in: Crônicas Brasileiras: A Reader [eds. Charles A. Perrone, Dário Borim Jr. e Celia Bianconi], Gainsville, EUA: UP of Florida, pp. 211-224. 
Ruffato, Luiz (2014). Minha primeira vez. Porto Alegre, Brasil: Arquipélago Editorial.

Santos, Joaquim Ferreira dos, ed. (2007). As cem melhores crônicas brasileiras. Rio de Janeiro: Objetiva.

Soares, Marcus Vinicius Nogueira (2014). A crônica brasileira do século XIX: Uma breve história. Biblioteca Humanidades. São Paulo: Realizações.

Werneck, Humberto (2005). Um gênero tipicamente brasileiro, in: Boa companhia: Crônicas [ed. Humberto Werneck], São Paulo: Companhia das Letras, pp. 7-12.

\section{The Urban Brazilian Crônica: A Subgenre in Transition}

With an emphasis on landscapes of urban lives, the objective of this study is to discover, unveil and define the nature and the crisscrossing of the main evolutionary lines of a subgenre of the Brazilian crônica. Along such paths of transition, we examine that growth of what we contemplate today as the contemporary crônica, a writing practice and form that gradually took shape after the coming of the Internet and the dissemination of the electronic media, whether it is a vehicle of social interaction, entertainment, news or information.

Key words: city, crônica, genre, jornalism, literature 
